\title{
El martirologio radical. Sentidos de la revolución y la democracia a inicios del siglo XX en Argentina ${ }^{1}$
}

\section{The martyrology of Radicalism. The significance of revolution and democracy at the beginning of the 20th century in Argentina}

\author{
Reyes, Francisco Jerónimo; Valdez, María José
}

Francisco Jerónimo Reyes

reyesfranciscoj@live.com

Instituto de Humanidades y Ciencias Sociales del Litoral. Universidad Nacional del Litoral - Consejo Nacional de Investigaciones Científicas y Técnicas, Argentina

María José Valdez majovaldez@gmail.com Instituto de Historia Argentina y Americana Dr. Emilio Ravignani. Universidad de Buenos Aires, Argentina

\section{Avances del Cesor \\ Universidad Nacional de Rosario, Argentina \\ ISSN: $1514-3899$ \\ ISSN-e: $2422-6580$ \\ Periodicidad: Semestral \\ vol. 18 , núm. 25, 2021 \\ revistaavancesdelcesor@ishir-conicet.gov.ar}

Recepción: 21 Mayo 2021

Aprobación: 30 Septiembre 2021

Publicación: 05 Diciembre 2021

URL: http://portal.amelica.org/ameli/jatsRepo/27/272643004/ index.html

DOI: https://doi.org/10.35305/ac.v18i25.1532

\section{(c) (i) (8)}

Esta obra está bajo una Licencia Creative Commons AtribuciónNoComercial 4.0 Internacional.
Resumen: El fenómeno de la sacralización de la política en la configuración de identidades nacional-populares constituye un objeto de estudio instalado en historiografías europeas, pero aún no consolidado en otros ámbitos. Este trabajo ensaya un aporte en esa clave centrado en la interpretación del pasado revolucionario de la Unión Cívica Radical (UCR) en la etapa de su llegada al poder en Argentina, momento en el cual la exaltación de sus muertos como "mártires" de una causa de regeneración se asoció a su éxito electoral y al proceso de democratización. Mediante el análisis de las principales formulaciones intelectuales de esa secuencia histórica, de conmemoraciones ritualizadas organizadas por la UCR a lo largo de una década y media, así como de una serie de acontecimientos particularmente conflictivos, se apela a un conjunto de fuentes que incluye, en especial, a la prensa militante y a la opositora, escritos de más largo aliento e imágenes que ilustran esas instancias. La hipótesis del artículo expresa que ese pasado revolucionario reflejó la popularidad del radicalismo pero luego se tornó particularmente problemático cuando los antagonismos intra y extrapartidarios derivaron en el golpe de Estado de 1930.

Palabras clave: Martirio político, Democracia de masas, Radicalismo, Revolución, Rituales políticos.

Abstract: The sacralization of politics as a central phenomenon in the configuration of national-popular identities is a well established subject matter in European historiography, but it is not yet consolidated elsewhere. Applying that theory, this article focuses on the interpretation of the Unión Cívica Radical's (UCR) revolutionary past during its accession to power in Argentina. The exaltation of their dead as 'martyrs' of a regeneration cause was often associated with its electoral success and the democratization process followed by the party. We analize the main intellectual formulations during this historical period, of the ritualized commemorations organized by the UCR, and of a series of particularly conflicting events. In that matter, we took into consideration partisan and opposing media pieces, texts of a wide scope and images which illustrate the period. The article hypothesis states that the revolutionary past of Radicalism was initially embodied in the popularity of the party, though it later 
became problematic when antagonisms within and outside the UCR led to the 1930 coup d'état.

Keywords: Political martyrdom, Mass democracy, Unión Cívica Radical, Revolution, Political rituals.

\section{Introducción}

Una inquietud que no ha sido abordada por la historiografía sobre el período de los gobiernos de la Unión Cívica Radical (en adelante, UCR) en Argentina, entre 1916 y 1930, se vincula con el lugar que ocupó el pasado revolucionario del partido en la nueva coyuntura, asociada a su transformación en fuerza predominante y a su apuesta democrática. Para los radicales no existía duda alguna de que sus triunfos se habían producido gracias a la expresión en las urnas de lo que consideraban la voluntad popular mayoritaria de la ciudadanía argentina. Pero concebían esa victoria como el punto de llegada de una misión histórica de regeneración política y moral de la nación gestada por los hitos revolucionarios de 1890, 1893 y 1905. Cada uno de ellos-según este imaginariopasó a formar parte de una secuencia y desde los mismos orígenes partidarios se exaltó a los caídos en combate como "mártires": civiles y militares que habían derramado su sangre y entregado su vida en "holocausto" de una causa reparadora. Por lo tanto, en esta memoria radical la democracia se había afirmado a través de la entrega y de la muerte de sus revolucionarios.

Desde hace varias décadas, una importante producción ha centrado su atención en el lugar que ocupó el culto a los mártires caídos (y de la violencia en sus distintas expresiones) en los fenómenos de sacralización de la política. Estos acompañaron a los procesos de democratización y al desarrollo de la política de masas entre finales del siglo XIX y las primeras décadas del XX en el mundo occidental -con un momento de inflexión indiscutido con la Gran Guerra-, asignando un estatus sagrado a sus respectivas causas. ${ }^{2}$ Los estudios sobre el radicalismo en esta etapa no se han detenido en este aspecto, que sí ha sido trabajado para la etapa previa (Persello, 2007; Reyes, 2016). Y aunque Tulio Halperin Donghi (2000) mencionó oportunamente la importancia del "apostolado" político esgrimido por el radicalismo como interpretación de sus triunfos electorales, lo hizo sin profundizar en sus distintas dimensiones e implicancias. El presente artículo propone pensar de qué manera el radicalismo en el poder apeló a esa dimensión simbólica y sostiene que la interpretación del pasado revolucionario y la exaltación de los “mártires radicales” tuvo un rol central en la legitimación del lugar del radicalismo en la democracia argentina. Pero, al mismo tiempo, su identidad política adquirió un carácter conflictivo, toda vez que los sentidos de aquel pasado revolucionario y de quienes lo habían protagonizado fueron resignificados por los diferentes sectores: el ejercicio del poder generó disputas que colocaron al partido gobernante en tensión. Así, el debate en torno a quiénes podían apelar al pasado sagrado fue un elemento clave para interpretar un presente crecientemente convulso.

En la primera parte, se analiza el lugar del martirologio radical en las elaboraciones intelectuales de algunos referentes del radicalismo que intentaron otorgarle un carácter de doctrina. En segundo lugar, se considera cómo se 
organizaron las conmemoraciones radicales de las revoluciones (en particular, las de 1890 y 1905$)^{3}$ en la Capital Federal en las décadas de 1910 y 1920 . Se examinan los cambios producidos en las mismas -tanto en su factura como en sus mensajesy la síntesis entre solemnidad y festividad que se adaptaba a las circunstancias de cada coyuntura. Por último, se presta especial atención a dos sucesos clave en los que pasado revolucionario y presente democrático confluyeron de forma conflictiva: la inauguración en 1925 del monumento a Leandro N. Alem, en un marco de disputas intrapartidarias; y los funerales de un militar y revolucionario radical, Eduardo Laurent, en un escenario marcado por el crescendo de la violencia política.

\section{Una doctrina del sacrificio}

Ya antes de su llegada al poder en octubre de 1916, el radicalismo había contribuido fuertemente a erigir a las revoluciones del cambio de siglo en lugares de la memoria, en parte, mediante una sostenida vigilancia conmemorativa de esos acontecimientos acaecidos en las dos décadas precedentes. ${ }^{4}$ Un fenómeno particular de sacralización de la política que, como en otras latitudes de la política occidental, cobró forma a partir de un culto a los combatientes caídos, a su heroísmo y su entrega, a la "sangre derramada en holocausto" de la "causa de la regeneración de la patria”. Ese esfuerzo incluyó negarle toda legitimidad a otras fuerzas políticas que también habían actuado en 1890 y 1893 (Reyes, 2016). Pero, no obstante estos antagonismos entre los "puros" y los "traidores" a la causa, esa memoria que valoraba los hechos de armas como hitos en la evolución política del país trascendía a los rangos de la UCR.

Para un amplio abanico de actores de la Argentina de inicios del siglo XX influyentes en la opinión pública- esos acontecimientos todavía temporalmente cercanos permanecían "calientes". Es el caso del destacado jurista, animador de la Revista Argentina de Ciencias Politicas y militante radical de la década de 1890, José Nicolás Matienzo, quien en el clima del Centenario de 1910 publicó su obra más importante, El gobierno representativo federal en la República Argentina. Este futuro funcionario de los gobiernos de Hipólito Yrigoyen (Procurador General de la Nación) y Marcelo de Alvear (Ministro del Interior) venía bregando como publicista por una regeneración político-institucional. Afirmaba que "la opinión pública manifestó la necesidad de mejorar el régimen electoral como medio de eliminar el motivo de la revolución armada". Anticipando a la que se conoció como Ley Sáenz Peña, que transformó de forma decisiva la normativa de los comicios, Matienzo reconocía que la revolución de 1890 había otorgado un impulso fundamental a "los procedimientos democráticos y liberales" en Argentina, generando una evolución modernizadora en las formas organizativas de los partidos políticos (Matienzo, [1910] 1917, pp. 238-239). Reflexión que no podía achacarse a un militante radical, ya que en esos años se encontraba fuera del radicalismo al que, sin embargo, concebía como producto de las aspiraciones reflejadas por los levantamientos armados.

En un tono diferente, aunque coincidente en la valoración, se expresó el popular semanario Caras y Caretas en un aniversario de la revolución del Parque antes de la reforma electoral. Si bien resultaba evidente que "entre la Argentina del 90 y la Argentina del Centenario no se pueden hallar más 
que puntos de divergencia", el cambio de actitud del radicalismo, que ya no hablaba de hacer una revolución, la presentaba como el mito fundacional que le otorgaba una "superioridad moral" sobre el resto de las fuerzas políticas y le permitiría capitalizar esa memoria colectiva: "El sacrificio de vidas que costó el 90 no ha sido, por lo tanto infructuoso: parece que los gobiernos tomaron cierta nota de aquella gran lección". 5 De esta manera, la voluntad de los gobernantes de cambiar las reglas del régimen político y transparentar prácticas electorales impugnadas aparecía como resultado de la muerte de los caídos en los combates revolucionarios. El recuerdo de los hechos de armas iba inextricablemente de la mano de una exaltación de los muertos, lo que en el imaginario radical se presentaba como el doloroso pero necesario costo por obtener una república democrática. Allí encontraban los miembros de la UCR el núcleo de su autoconcepción como los únicos destinados a conducir la nueva etapa.

¿Cómo formularon los radicales su interpretación del pasado revolucionario cuando finalmente se abrió la perspectiva del poder político, primero en las provincias y luego en las elecciones presidenciales que consagraron a Hipólito Yrigoyen en 1916? No cabe duda de que para la UCR los triunfos obtenidos desde 1912 constituían, a la vez que un punto de llegada de lo que consideraban su "resistencia" previa a los gobiernos de la "oligarquía", una verdadera refundación de la república (Aboy Carlés, 2005). ${ }^{6}$ Una "nueva era" de "reparación" que formaba parte de una secuencia y que podía retrotraerse al ciclo 1890-1893-1905 e incluso a 1853 (inicio de la organización constitucional) y 1810 (la Revolución de Mayo).

Además de las prácticas conmemorativas que se sucedieron anualmente con un celo ritualizado - analizadas en el apartado siguiente-, en la consolidación de estas convicciones jugaron un papel destacado algunas elaboraciones intelectualmente más ambiciosas de dirigentes y publicistas vinculados al radicalismo. Una serie de ejemplos ilustran estos raros intentos de sistematizar un imaginario militante que se alimentaba más de los discursos de sus líderes (en diferentes niveles), de la retórica propia de las actividades de comités de base y de la prédica más regular de los periódicos partidarios, que de obras que se pretendían fundadas en teorías de largo aliento, como sucedía con el Partido Socialista (en adelante, PS). ${ }^{7}$ En sendas obras de Horacio Oyhanarte y José Bianco -mediadas una de otra por casi una década- esa nueva etapa que se pensaba como una democratización encabezada por la UCR formaba parte de una narrativa en donde la popularidad del partido en las urnas era resultado directo de los sacrificios que se habían realizado mediante las revoluciones y la abstención electoral.

En vísperas de las presidenciales de 1916, el por entonces diputado nacional Oyhanarte escribió un grueso tomo titulado simplemente El Hombre, en alusión al candidato radical Yrigoyen. Este libro de campaña, sonoramente anunciado por la prensa militante, ${ }^{8}$ conoció varias ediciones y ha sido usualmente analizado como insumo característico de la construcción del liderazgo mesiánico de aquel (Halperin Donghi, 2000; Padoan, 2002). Sin embargo, la exégesis que según Oyhanarte conducía a un inexorable triunfo de la UCR se centraba en los hitos revolucionarios y sus implicancias para el presente en un sentido espiritual que trascendía al propio partido: "La revolución ha sido el Calvario sobre cuya arena teñida de rojo, han peregrinado los pueblos, se han sublimado las naciones, se 
han inmortalizado las razas" (Oyhanarte, 1916, p. 72). La alusión a la sangre derramada en los levantamientos armados los exaltaba como continuación de las luchas que habían dado forma a la República. Pero actuaba como un recuerdo para los sobrevivientes que debían rendir gratitud a los muertos y llevar hasta sus últimas consecuencias la promesa regeneracionista:

Eran apóstoles y pasan a ser mártires, uniendo sus sacrificios al de los que les han precedido, en holocausto de los más sagrados ideales de la patria, dejando en las filas de la Unión Cívica Radical, claros imperecederos. Ellos reposarán al amparo del reconocimiento público y del respeto de la posteridad (pp. 92-93).

El sentido pedagógico de este tipo de textos dedicado "a la juventud” operaba también un dinamismo profético que alimentaba la mitología política del radicalismo como la fuerza del futuro: "Este presente es aquel pasado y será también el grandioso porvenir” (p. 99). Aun así, no desentonaba con lo expresado por su autor en otros ámbitos, como su primer discurso en la Cámara de Diputados de la Nación en 1914 donde expresó que el objetivo del radicalismo era el "resurgimiento de esas instituciones que han sido amasadas con sangre, que han sido exponente de altiveces. Eso vamos buscando a lo largo de esta reparación histórica que sintetiza el credo de la Unión Cívica Radical” (Oyhanarte, 1999, p. 49). En esa concepción del núcleo de la identidad radical como creencia o, mejor aún, como una religión cívica -con su lenguaje específico, la definición de una misión histórica y la ritualización de sus prácticas conmemorativas ${ }^{9}$ - resulta elocuente que al cerrar la Convención Nacional del partido que terminó por definir la candidatura de Yrigoyen, Oyhanarte iniciara con un minuto de silencio en homenaje a la "memoria de los caídos por la causa", antes de una masiva manifestación callejera hasta el domicilio del elegido. ${ }^{10}$

A diferencia de aquellos discursos que focalizaban en la filiación con ciertas tradiciones y doctrinas políticas (el republicanismo o el liberalismo), en el mensaje producido y consumido por los radicales primaba una argumentación teñida de motivos emocionales. Incluso cuando los muertos y su sangre derramada se asociaban a la historia política nacional aparecían en un primer plano por sobre los aspectos más ideológicamente elaborados. De ello eran conscientes algunos de voceros de la oposición que se fue articulando en los primeros años de la presidencia de Yrigoyen, como el diario La Nación, antiguo órgano del mitrismo que se disputara con los radicales en la década de 1890 la reivindicación de la revolución del Parque. Como lo expresara en la previa a las elecciones de 1922, aún en sentido contrario, esta mirada confirmaba las convicciones de los militantes de la UCR:

La historia del martirologio radical, tantas veces mentada en el periodo de las conspiraciones revolucionarias, debió lógicamente cerrarse una vez que la conquista del Poder hubo asegurado el advenimiento feliz de la era nueva. En estricta verdad, las persecuciones y los sacrificios sobrellevados durante la lucha contra el régimen sólo aparecían en la fantasía exaltada de la literatura partidista. (...) Pero una leyenda, revestida con la autoridad de la cosa juzgada, quiso consagrar, como atributo dominante de los consabidos treinta años, los sufrimientos heroicos y las privaciones ascéticas de los adeptos a la nueva fe. A fuerza de repetirla es presumible que ellos mismos hayan acabado por creerla. ${ }^{11}$ 
En un libro que se volvería célebre entre los radicales como síntesis del derrotero del radicalismo desde la oposición al ejercicio del poder, La doctrina radical, José Bianco afirmaba promediando la presidencia de Alvear que dicho ideario constituía antes que nada la síntesis de cuarenta años de "esfuerzos reparatorios en el largo andar, cuyos puntos de partida se inician con los movimientos cívicos" (las revoluciones). Al igual que Oyhanarte, para este profesor de Historia de las Instituciones Representativas en la Universidad de La Plata, luego de una larga militancia en la UCR -secretario del Comité Nacional en la década de 1890 y de Bernardo de Irigoyen en la gobernación de la provincia de Buenos Aires- la obra del radicalismo venía a cumplir en Argentina una misión histórica de carácter nacional signada por la huella de sus muertos: "Todas las naciones señalan, en la evolución histórica, esa trayectoria doctrinaria que se idealiza con el sacrificio y se ennoblece con el martirio" (Bianco, 1927, p. 7). Todo este devenir, entendido como escatología religiosa, desembocaba en "el renacimiento social y la redención política". El libro contenía capítulos que ejemplificaban esa obra de los gobiernos radicales en materia de política social, relaciones internacionales, el vínculo gobierno nacional/gobiernos provinciales, el desarrollo de los ferrocarriles y la política petrolera. Pero la forma en que se transmitía esta doctrina tenía como hilo conductor ese mandato sacrificial que el autor había anticipado en una conferencia del Centro de Estudiantes de Derecho de la universidad platense: "Debe mantenerse el concepto con las tradiciones y los sacrificios heroicos, para no perder la orientación iniciada por la independencia argentina, confirmada por la organización nacional, encarnecida por el régimen y restaurada por el triunfo de la Unión Cívica Radical” (pp. 7, 98-99 y 101).

Dicho mandato, construido a partir de las figuras idealizadas de los combatientes radicales en tanto ciudadanos-soldados y de sus muertos como mártires, imponía un conjunto de creencias y valores a quienes se identificaban con la UCR en el gobierno. Esto definió una relación particularmente demandante para los militantes, una base de fieles que debía continuar esa obra de "reparación institucional". Ciertamente fue a través de un amplio repertorio de prácticas conmemorativas, que interpelaba a distintos actores desde diversos registros, que se consolidó una identidad política propia de un movimiento nacional-popular de masas.

\section{La diversificación de los rituales conmemorativos}

Como se ha señalado, el radicalismo construyó un calendario de efemérides en el que un conjunto de fechas ocupó un lugar central, operación de vigilancia conmemorativa que se transformó en uno de los elementos constitutivos de la memoria radical convertida en religión cívica. Como han demostrado diferentes estudios focalizados en la construcción de identidades colectivas luego de la Revolución Francesa, las conmemoraciones de acontecimientos y fechas-símbolo convirtieron a los cementerios y monumentos en espacios sacros para las "comunidades de creyentes" que rendían tributo a los caídos, afianzando lazos entre sí (Prost, 1997; Koselleck, 1998). Una identidad nacional-popular como la del radicalismo no escapó a este fenómeno transnacional, pero llegado al poder sus conmemoraciones partidarias comenzaron a adquirir otro cariz, no obstante 
lo cual, sus adherentes interpretaron la nueva etapa desde el aparato simbólico de sus años fundacionales.

En paralelo a la evocación del sacrificio de los mártires, las guardias de honor en los camposantos o la colocación de flores en las tumbas de los caídos, los actos se nutrieron de un carácter autocelebratorio que contrastaba con la gravedad de las conmemoraciones de 1890 en las que, además de los cementerios, las misas en las iglesias habían sido moneda corriente (Reyes, 2016). Aunque válida analíticamente, la diferenciación entre el carácter luctuoso o festivo no explica cabalmente la complejidad del fenómeno. La potencia de la mitología radical estribaba precisamente en que los aspectos privados del culto a los muertos se prolongaban en celebraciones partidarias. Formaban parte de una misma secuencia que incluía como espacios de homenaje el cementerio, locales cerrados (teatros y comités partidarios) y, posteriormente, la calle como escenario de desfiles que culminaban en lugares como el Comité Nacional.

Por otro lado, el culto a los muertos se asoció a las prácticas propias de la política de masas que, en general, procedían del período finisecular. Estas se consolidaron y acompasaron con la concurrencia electoral regular: en muchas ocasiones, conmemoración y campaña electoral fueron de la mano. Así, la evocación del pasado se vinculó con la celebración de triunfos en los comicios que se sucedieron en diferentes provincias, con "veladas cívicas" que incluían conferencias políticas, números artísticos y entretenimientos familiares. En ese marco, la celebración era un mecanismo clave para mantener viva la conmemoración y otorgarle un nuevo sentido. Además, con la manifestación callejera de una multitud producida frente a un público espectador no partidario, este indirectamente era transformado en partícipe de aquello que se conmemoraba. ${ }^{12}$

Los 4 de febrero y los 26 de julio los cementerios de Recoleta y Chacarita se convirtieron en lugares privilegiados para la conmemoración. La designación de guardias de honor por los comités de la Capital -turnados en la tarea- entre legisladores nacionales y dirigentes destacados fue uno de sus rasgos salientes. En plena campaña para la elección presidencial de 1916, los diputados Víctor Molina y Délfor del Valle fueron designados por el Centro Patriótico Radical como oradores por la revolución de 1905 en la Chacarita, ${ }^{13}$ mientras que el comité de Balvanera Norte organizó un acto nocturno para homenajear el triunfo a gobernador en las elecciones de Córdoba, con Eufrasio Loza, Diego Luis Molinari (presidente del Comité Universitario Radical), José Luis Cantilo y Elpidio González como oradores. ${ }^{14}$

En 1919, con Yrigoyen presidente, el Comité Capital nombró oradores para ambos cementerios y entre las guardias de honor participaron varios oficiales del Ejército, en tanto los militares retirados y dados de baja que habían tomado parte en la revolución de 1905 realizaron un homenaje a los compañeros de armas caídos en el mausoleo de Recoleta con discurso de Leopoldo Bard. ${ }^{15}$ Meses más tarde se definieron guardias por el aniversario de la revolución del Parque, donde el comité de la $15^{\circ}$ designó al diputado Francisco Beiró al tiempo que Del Valle disertó en el acto central. ${ }^{16}$ 


\section{Imagen 1}

Conmemoración de la revolución de 1890 en el Cementerio de la Recoleta

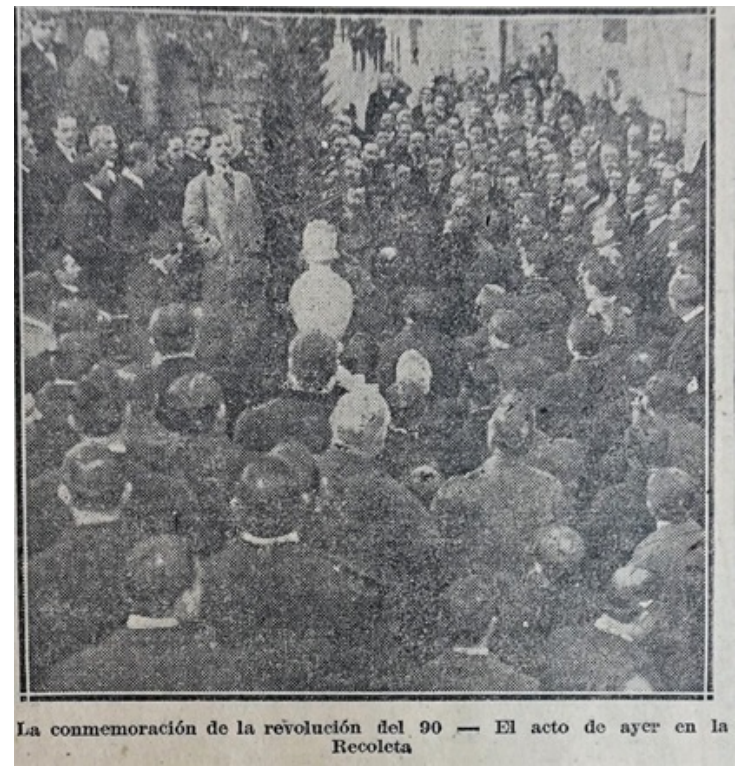

Fuente: (27 de julio de 1919). La Época. BNRA, CABA.

En 1923, un grupo de estudiantes universitarios radicales designó su propia guardia de honor para el monumento, ${ }^{17}$ mientras que a los comités seccionales sumaron guardias el Centro de Revolucionarios Radicales Militares y Civiles, el Ateneo Universitario Radical y la biblioteca "Marcelo de Alvear". ${ }^{18}$ Lo mismo había ocurrido antes por la conmemoración de 1905: el club "Aristóbulo del Valle” organizó en la Recoleta una celebración junto al Centro de Damas Descendientes de ex Revolucionarios que contó con la recitación de la poesía “Alem” por una niña, el discurso de su presidenta María Luisa R. de García y varios dirigentes partidarios. ${ }^{19}$ Algo no consignado por el diario yrigoyenista $\mathrm{La}$ Época fue que para la ocasión el Centro designó vice-presidenta honoraria a la primera dama, Regina Pacini de Alvear. ${ }^{20}$

En la celebración por el Parque de 1929 el Comité Capital personalista definió una guardia integrada por los presidentes de los comités seccionales, al tiempo que concejales y los diputados nacionales Bard y Pedro Bidegain participaron junto al Comité Femenino Radical, que rindió -según la crónica- "justo homenaje a los precursores de nuestra democracia”, con discurso de su presidenta Justina C. de Gary. Incluso la reunión de la Convención de la UCR porteña resolvió que todos sus miembros hicieran guardia. ${ }^{21}$ La importancia de estas participaciones, en donde los dirigentes - de larga prosapia algunos, nuevos otros-actuaban como un militante más, radicaba en la confirmación del vínculo colectivo con ese pasado heroico, un plus de legitimación al reforzar el sentido de pertenencia a la comunidad radical.

Otro conjunto de actividades conmemorativas fueron organizadas por los comités seccionales o el de la Capital en teatros o salones y se transformaron en ocasiones de comunión entre los participantes. En primer lugar, simbolizaban una recuperación del pasado para reafirmar el presente democrático y proyectar hacia el futuro el predominio alcanzado por la UCR. Un juego temporal inherente al carácter dinámico de todo ritual político al aportar un sentido 
de continuidad a las experiencias de los sujetos que deben lidiar con nuevos desafíos en las luchas por el poder (Kertzer, 1988, pp. 9-10). En segundo lugar, estas celebraciones funcionaban como soldadura de la solidaridad militante en diferentes contextos: previo a la ruptura de la UCR, frente a los disensos internos, frente a los opositores (principalmente los socialistas) y, luego de 1924, ante un "otro" que también se reconocía como radical: el antipersonalismo. De esta manera, las conmemoraciones personalistas se propusieron confirmar quiénes representaban al verdadero radicalismo a través de la reivindicación del pasado heroico y del culto a los caídos. Pero también las evocaciones ubicaban la obra de gobierno radical (en especial de Yrigoyen) en una secuencia histórica iniciada con el Parque, seguida en 1905 y consolidada en 1916. Una obra en permanente construcción que requería del sacrificio de los fieles por la causa para no quedar inconclusa.

Las conmemoraciones de las décadas de 1910 y 1920 permiten advertir cómo la memoria de las revoluciones y los caídos se vinculaba a la coyuntura electoral para formar parte de un mismo repertorio que se potenciaba simbólicamente. La conmemoración de la revolución de febrero para 1916 tuvo epicentro en los cementerios, pero también se organizaron actos en algunas circunscripciones. Así, en el citado acto del comité de Balvanera Norte luego se desfiló hasta el Comité Nacional con los diputados Del Valle, Tomás Le Bretón y Rogelio Araya como oradores. ${ }^{22}$ El subcomité “Capitán Miguel González” de la $3^{\circ}$ realizó una conferencia en la que Restituto Caraza habló sobre el futuro triunfo de Yrigoyen y Alejandro Hayes invitó a un "religioso descubrimiento" en memoria de González. En el comité de la $10^{\circ}$ habló Le Bretón con críticas a los diputados socialistas y Guillermo Sullivan los calificó de "sectarios", mientras Virgilio Paternoster enfatizó en propagar el "credo radical". 23

En la conmemoración del Parque realizada con Yrigoyen electo, Tomasa Alem -hermana de Leandro- cedió al club "Alem” la bandera de 1890 que guardaba como una reliquia, portada simbólicamente por militantes con boinas blancas. Meses más tarde, el Manifiesto del Comité Capital para la manifestación de asunción presidencial señaló que el triunfo era "Obra de reparación institucional y educación popular; obra de genuina orientación democrática (...) necesitó obreros, que olvidando el éxito, supieron ofrendarse a la patria, en holocausto reivindicatorio". ${ }^{24}$ Esta asociación en el imaginario radical de una continuidad entre los mártires revolucionarios y el éxito electoral emergió en un editorial de La Época de 1919 dedicado al acontecimiento fundacional. El Parque anticipaba el presente: "los ideales proclamados el 26 de julio (...) constituyeron su bandera de rebelión, su divisa, su moral suprema y consiguió imponerlos de manera definitiva en 1916 (...) con el sagrado fervor que inspiran sus ideales realizados" ${ }^{25}$ 


\section{Imagen 2}

Manifestación en conmemoración de la Revolución del Parque

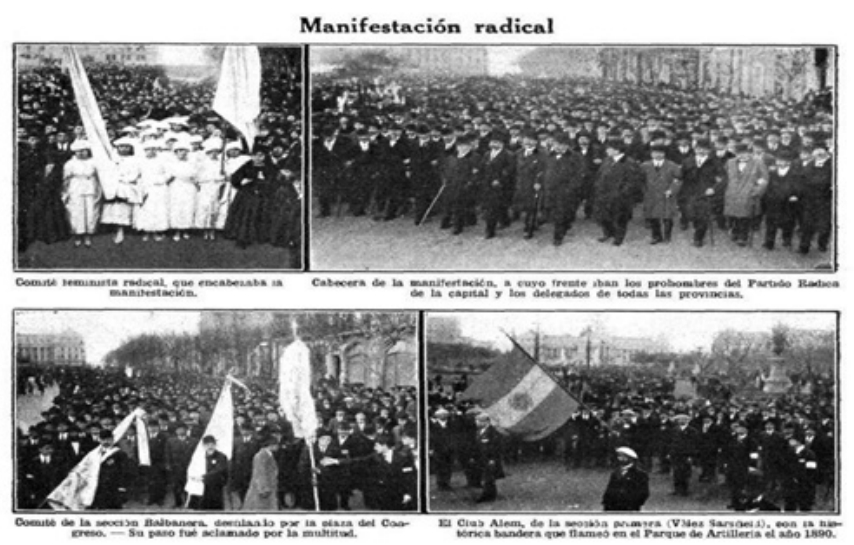

Fuente: (2 de agosto de 1916). Caras y Caretas. BNRA, CABA.

La conmemoración de la revolución de 1905 organizada en 1926 por el comité de la $12^{\circ}$ constó de una manifestación hasta el domicilio de Yrigoyen, mientras que Bard se refirió a la obra de gobierno en favor de los obreros, en plena competencia con el socialismo por el electorado trabajador porteño. ${ }^{26}$ En el acto principal en el teatro Coliseo, con unas 7000 personas, se entonó el Himno Nacional y los dirigentes se refirieron a los "sacrificios del alma popular", para cerrar con una manifestación hasta el Comité Capital coreando "canciones populares del partido” y “ivivas!” a Yrigoyen. Del Valle consideró a la revolución de febrero como "el acontecimiento más trascendental que desde la organización nacional se haya producido y para contemplarlo como el génesis de todas las conquistas democráticas alcanzadas por el esfuerzo de la Unión Cívica Radical”. A la conocida profecía y exaltación del sacrificio, sumó una referencia a la fractura partidaria ocurrida dos años antes. En medio de la campaña electoral, era ocasión para reivindicar al "verdadero" radicalismo y afianzar la tradición sistematizada por obras como las de Oyhanarte y la de Bianco:

\footnotetext{
nunca como en esta hora, era oportuna la conmemoración de ese gran esfuerzo, cuando la Unión Cívica Radical se ha sentido amenazada en su integridad, por la traición dentro de sus filas, cuyos tránsfugas habían ido a formar con los hombres del "régimen" el odioso contubernio que ponía en peligro todos los grandes bienes alcanzados por la República bajo los auspicios del primer gobierno radical. ${ }^{27}$
}

Como se adelantó, una vez en el gobierno las conmemoraciones radicales incorporaron elementos festivos, algo que ya venían realizando con éxito para los $1^{\circ}$ de Mayo los socialistas y también en los años 1920 los comunistas (Reyes, en prensa; Camarero, 2007). En esta transformación del ritual partidario las celebraciones se proponían integrar a toda la "familia radical": no sólo afiliados sino también a sus mujeres e hijos, hermanados en la causa partidaria que era, simultáneamente, la del gobierno que pretendía inaugurar una nueva era para la nación. En 1918, a las visitas a los cementerios se sumaron algunas veladas festivas por la revolución de 1905, como la del club "Baluarte Radical” en el cine-teatro Saavedra que incluyó sinfonía por orquesta, cinematógrafo, discurso de Edelmiro Segarra, canto femenino, baile clásico español, tenor, concierto de guitarra, saltarín de toneles y al "payador argentino" Generoso Damato. ${ }^{28}$ 
Un año más tarde, en recuerdo de 1890 , el comité de la $9^{\circ}$ organizó una gran velada nocturna en el teatro Exelsior con conferencia de Carlos Massuco y actuaciones de la compañía dramática Rivera-De Rosas. Por su parte, el programa de la "velada literario-musical" del comité de la $20^{\circ}$ sumó orquesta, parodia napolitana, violín y piano, danza española, ventrílocuo y concierto de guitarra. ${ }^{29}$ Las fotografías publicadas por La Época captaron atentamente el regocijo de las familias radicales.

Estos bemoles de las conmemoraciones y la necesidad de intercalar, con la solemnidad tributada, los más obvios motivos en clave nacional y entretenimientos dirigidos a los sectores populares se reflejaron especialmente en el 31 aniversario del Parque. La velada del comité de la $11^{\circ}$ en el teatro Standard tuvo como colofón la inauguración de los "consultorios médicos para pobres” montados en el local partidario, en tanto Del Valle se refirió a la difícil vida de Alem como niño marginado convertido redentoramente en ejemplo para la democracia. La tónica estaba dada por el "obrerismo radical”, una serie de iniciativas motorizadas desde los comités seccionales (con consultorios profesionales) y por la acción de los gobiernos de Yrigoyen y Alvear que habían avanzado en una "legislación social" dirigida a los trabajadores, parte significativa de la base electoral radical (Horowitz, 2015). Las conmemoraciones, al igual que las campañas electorales, eran propicias para difundir estas propuestas, con invectivas contra el socialismo entendido por los radicales como una fuerza antinacional.

Pero no todo tenía que ver con el sentido dramático/emotivo del recuerdo de los mártires o con el incipiente contenido social de la labor de la UCR. El disfrute no podía estar ausente si se trataba de interpelar a algo más que los votantes; de allí la panoplia de actividades señaladas: proyección de películas, monólogos, orquestas sinfónicas, números cómicos, reproducción de escenas gauchescas y cantos con bailes nacionales. Algunos artistas ensayaban actos de transformismo e imitaciones de "estrellas porteñas” y González - "el primer ventrílocuo argentino" - se desempeñó con sus "autómatas parlantes" antes de María Blasco -"Reina de la jota"-. En 1921 los comités $12^{\circ}, 13^{\circ}$ y $14^{\circ}$ organizaron su velada en el Orfeón Español con toda la parafernalia ritual: busto de Yrigoyen, retratos de Alem y Aristóbulo Del Valle, banderas nacionales y la del Parque con guardia de honor. En presencia de la "Juventud Radical Hipólito Yrigoyen", se entonó el Himno Nacional, se escucharon los discursos de Hipólito Leys, Bard (señaló que "Alem fue el alma de esa revolución regeneradora, en que confundieron sacrosantos ideales, el pueblo y el ejército”) y Leónidas Anastasi exponente del obrerismo radical y futuro antipersonalista que en 1923 presentó un proyecto de ley de jornada laboral de 8 horas-. El acto finalizó con una manifestación hasta la casa de Yrigoyen donde, nuevamente, se entonaron las estrofas del Himno Nacional. ${ }^{30}$ 


\section{Imagen 3}

Velada nocturna del comité de la UCR de la $20^{\circ}$ circunscripción de Capital Federal

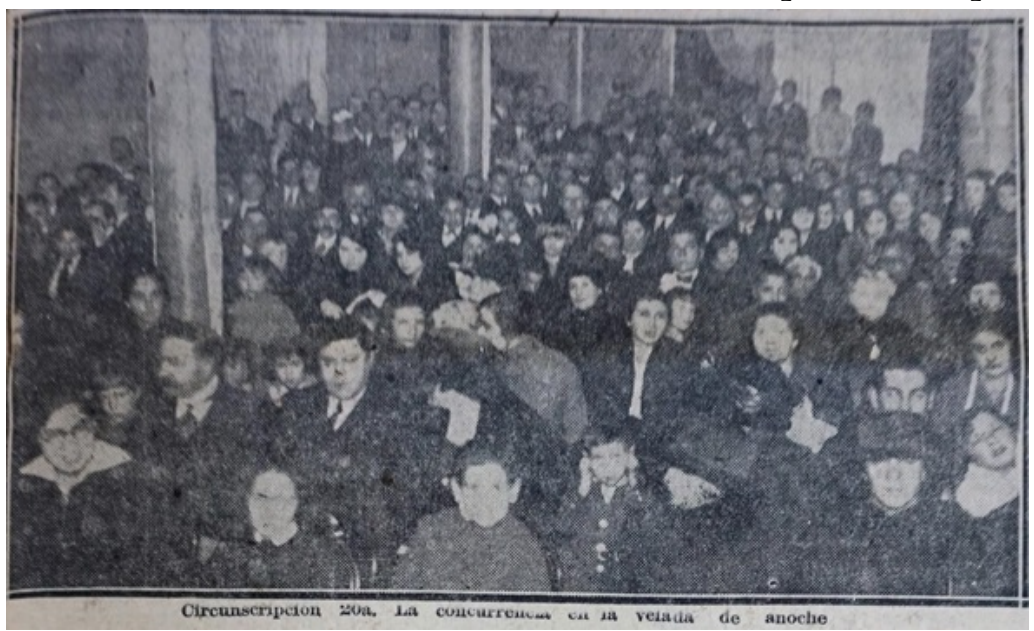

Fuente: (27 de julio de 1919). La Época. BNRA. CABA.

No obstante estas dimensiones que se fueron afianzando, las conmemoraciones no escaparon a la escalada de la polarización de finales de los años 1920. Dicha polarización estuvo marcada por el ascenso de diferentes sectores de derechas que, en esta coyuntura, se entremezclaron y confluyeron en oposición al líder radical. ${ }^{31}$ Como se sabe, el de yrigoyenismo/antiyrigoyenismo debe considerarse como un clivaje fundamental - pero no el único- para comprender la conflictividad política de aquellos años. Entre los diferentes grupos radicales, la hostilidad cada vez más manifiesta condujo a que para 1928 el homenaje de febrero se suspendiera por orden de Yrigoyen, debido a la exacerbación de las pasiones por unos sucesos en Santa Fe y por los enfrentamientos entre personalistas y anti-yrigoyenistas en Capital Federal. Este fue el clima general de la campaña electoral en que aquel fue reelecto, la que se redujo a una mínima expresión ante uno de los rasgos centrales que había adquirido la lucha política: la violencia física (González Alemán, 2014). Todo esto lleva a interrogarse si una ritualidad, unas memorias y una identidad centradas en un pasado revolucionario como en el radicalismo, con su culto a la lucha sacrificial y la "sangre derramada" como valores ejemplificadores para los militantes, no tuvieron consecuencias en las diferencias que desgarraron a la UCR.

\section{¿De quiénes son los muertos? Presente en conflicto, pasados en disputa}

Dos acontecimientos del segundo lustro de la década de 1920 permiten calibrar la agudización de las tensiones latentes que los primeros éxitos electorales del radicalismo apenas habían logrado velar. En primer lugar, si las conmemoraciones de las revoluciones organizadas por la UCR constituyeron las instancias por excelencia de la puesta en escena de la mitología radical en torno a los caídos, el culto a la figura de Alem también formaba parte del calendario radical. Desde su muerte en 1896 y a partir de su primer aniversario, el dirigente revolucionario -cuyo suicidio él mismo interpretó en su "testamento político" como un acto 
de entrega- ocupó el lugar de principal mártir del radicalismo, el profeta de una regeneración moral de la política argentina que se juzgaba inexorable (Reyes, 2016). La visita a su tumba en el mausoleo a los caídos en la Recoleta y los discursos por el $1^{\circ}$ de julio lo convirtieron en un símbolo transversal a los distintos sectores de la UCR. Ubicuidad que incubaba la disputa por la legitimidad de venerar su memoria, sobre todo con la llegada del radicalismo al poder.

La concreción en 1925 del proyecto largamente postergado de un monumento dedicado a Alem en Capital Federal fue un punto álgido en el proceso de ruptura de la UCR, con la conformación de la UCR Antipersonalista, planteándose la cuestión de quiénes podían reivindicar y ser fieles a su figura para representar los valores que supuestamente había encarnado. Es cierto que existían ya monumentos en su honor en Junín (1918), el Parque Independencia de Rosario (1922), uno proyectado para la capital tucumana y otro que se inauguraría pronto en la localidad bonaerense de San Fernando (1926) (Alem, 1928), pero no caben dudas que el de la ciudad más importante del país contenía todas las expectativas.

Los avatares del proyecto contuvieron tempranamente aquellas tensiones. Antes del primer aniversario, el Comité Capital levantó una suscripción para costear la obra, quedando a cargo el por entonces presidente del Comité Nacional, Bernardo de Irigoyen, pero poco después sus adversarios que encabezaron la reorganización partidaria denunciaron la inacción del dirigente como una "traición". ${ }^{32}$ En los años siguientes hubo múltiples intentos por reflotar la iniciativa, aunque el impulso definitivo se dio en 1918 al reunirse un conjunto de referentes, en donde el diputado Vicente Gallo propuso una convocatoria “amplia”. El presidente del Comité Nacional, Araya, fue nombrado presidente de la nueva comisión, pero una exaltación pública de Alem que hiciera poco después fue interpretada por los seguidores de Yrigoyen como una crítica a su estilo de conducción (Persello, 2007, pp. 53-54). En ese clima de rencillas entre los radicales se sucedieron rápidamente varias renuncias a la comisión. ${ }^{33}$

La carga identitaria que contenía un homenaje considerado sagrado tornaba casi imposible que las desventuras de la obra no se cruzaran con diferencias que parecían cada vez más insalvables. Además de los avances realizados por las comisiones pro-monumento de los comités seccionales del radicalismo porteño, una nueva Junta Central presidida por un amigo de Alem -el senador Martín Torino- se puso en contacto con empresarios teatrales que ofrecieron funciones para recaudar los fondos que faltaban, en el marco del aniversario de la revolución del Parque para 1920 que se denominó "Día Alem” y en el cual se organizó una "gran colecta popular". ${ }^{4}$ Todo esto agigantó las ansiedades en torno a la figurasímbolo.

El grupo escultórico ubicado frente a plaza San Martín -Alem emergiendo junto a una mujer/República y dos piezas que representan a la Juventud Radicalfue encargado al artista Pedro Zonza Briano y, de acuerdo a un folleto de la comisión, se afirmaba que el Estado nacional no había aportado fondos para el monumento inaugurado el 10 de octubre de $1925 .{ }^{35}$ La elección del lugar de emplazamiento pretendía elevar al viejo líder de la UCR a las alturas de un panteón nacional que lo precedía, entroncándose de forma algo tardía con la proliferación monumental y estatuaria que tuvo su cénit en las conmemoraciones de los Centenarios de 1910 y 1916 (Gorelik, 2010, pp. 206-212). Un acto 
partidario, sí, pero en una secuencia en donde el patriotismo radical venía a consumar una secuencia histórico-política de largo aliento.

Este fue un acontecimiento propio de la política de masas -su asistencia se estimó en 60.000 personas- pero tenía antecedentes en los funerales de Estado de lo que Sandra Gayol denominó la "celebración de los grandes hombres" en la Argentina de las primeras décadas del siglo XX (Gayol, 2012). La mentada ausencia estatal resultó ambigua, porque Alvear estableció por decreto presidencial la inauguración del monumento a Alem -un dirigente partidario, no estrictamente un hombre de Estado-, lo que conllevó "honores reglamentarios" de distintos cuerpos militares. Esta apoteosis póstuma lo ubicaba en un lugar singular de la historia nacional y de la UCR en particular, mientras que la denominación de "profeta" o "apóstol" de la democracia venía a confirmar la justificación retrospectiva de las revoluciones del cambio de siglo y, en consecuencia, del lugar del radicalismo refrendado en las urnas.

\section{Imagen 4}

Inauguración del monumento a Alem en Capital Federal INAUGURACION DEL MONUMENTO A ALEM

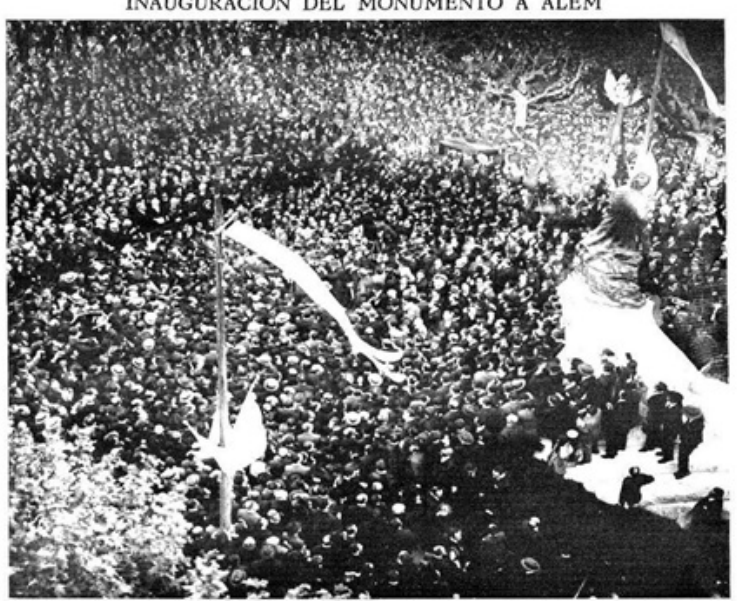

Fuente: (17 de octubre de 1925). Caras y Caretas. BNRA, CABA.

La significación del acto para los radicales no podía ser mayor. La presencia junto a Alvear de los ministros antipersonalistas Agustín Justo (Guerra) y Roberto Ortíz (Obras Públicas) demostraba la fragmentación del pasado compartido. El palco debajo del monumento se completó con familiares de Alem, el ministro del Interior José Tamborini, el intendente porteño Carlos Noel, Torino, el teniente coronel Aníbal Villamayor (por la Junta de Sobrevivientes de la Revolución del Parque) y un nutrido grupo de senadores y diputados radicales. Sintomáticamente, entre la multitud sólo se presentó un comité yrigoyenista (el de la $20^{\circ}$ ). El discurso principal de Tamborini ubicó a Alem en la estela de los "padres fundadores" de la República, como Alberdi y Sarmiento. Pero, en cambio, había jugado un papel anticipatorio que lo diferenciaba de las "clases dirigentes": "estaba llamado a ser (...) el que señalaría para nuestro pueblo la iniciación de un período de nuestra historia" al identificarse "directamente con el alma popular". Por eso -finalizaba- "cumplió su tarea de poner en función al ciudadano de nuestra democracia”. 36

Un mensaje que podía ser compartido por radicales de distinto pelaje, en tanto todos otorgaban un sentido refundacional a la llegada del radicalismo al poder. 
Lo que motorizó algunos incidentes fue la decisión de Yrigoyen de observar el acto desde un carruaje y no desde el palco. De forma que al finalizar los oradores un grupo de personalistas copó el palco al grito de "traidor" y "tránsfuga" contra Torino y Alvear, mientras vivaban al ex presidente, algo que fue señalado por la más dura prensa anti-yrigoyenista. ${ }^{37}$ La reacción de los antipersonalistas se dio en un editorial de La Acción y parece difícil separar la disputa intra-radical de las emociones suscitadas por el acto, pero también de las pasiones propias del clivaje personalismo/antipersonalismo. De acuerdo al periódico, la actitud de los personalistas, en vez de fidelizar la memoria de Alem, entrañaba peligros futuros:

Y ahí, frente a la estatua del apóstol, mártir de sus propias ideas, que dio todo lo que humanamente se puede exigir a un hombre (...) 'su última sangre y el resto de su vida', no desde luego para evocar la figura del maestro, cuyo perfil en prosa digna acababa de burilar el doctor Tamborini; no para exaltar el culto de su memoria (...) hablaron para saludar a la distancia el advenimiento de una ilusoria dictadura. ${ }^{38}$

Un segundo acontecimiento, rápidamente connotado por las caracterizaciones del martirologio radical, terminó por patentizar diferencias que rompieron definitivamente toda solidaridad en torno a esas memorias compartidas. A comienzos de 1928, en medio de la campaña electoral por la renovación de la primera magistratura, un hecho ocurrido en la localidad santafesina de Máximo Paz (a pocos días de la elección provincial) sacudió la política nacional: el asesinato del capitán Eduardo Laurent. Este militar retirado había participado de las revoluciones radicales de 1893 y de 1905, lo que lo colocaba en un lugar destacado en la historia heroica del partido. ${ }^{39}$ En 1928 Laurent, junto al diputado nacional Pascual Subiza y otros dirigentes, había sido comisionado para fiscalizar los comicios santafesinos en los departamentos de Constitución y General López (Peretti, 2016, p. 28). Santa Fe era un distrito crucial en el camino de retorno de Yrigoyen al poder, luego de triunfos personalistas para gobernador en Salta y Tucumán.

El 1 de febrero, en una emboscada perpetrada por la policía de Máximo Paz en connivencia con las autoridades locales antipersonalistas, ${ }^{40}$ Laurent fue asesinado a balazos. El suceso perturbó a la agitada política provincial al producir una fuerte movilización de denuncia por el yrigoyenismo local y nacional. De hecho, los diputados Bard y Gamarra, comisionados por el Comité Nacional, viajaron a Santa Fe para investigar lo sucedido y trasladar el cuerpo de Laurent en tren hacia Capital Federal, hecho que ocurrió simbólicamente el 4 de febrero. Un día antes, La Época había anunciado que

Las altas direcciones de la Unión Cívica Radical, han resuelto postergar para otra fecha el mitin y otros actos que pensaban realizarse el domingo próximo con motivo de cumplirse el 23 aniversario del movimiento revolucionario del 4 de febrero (...)

las autoridades del partido han obedecido a motivos de prudencia, pues dada la exaltación que reina entre nuestros correligionarios, por los atropellos, violencias y crímenes de que son víctimas en Santa Fe, por su brutal gobierno, los afiliados de la Unión Cívica Radical, en vísperas de los comicios a realizarse el próximo domingo, podrían producirse incidentes inevitables. ${ }^{41}$

Las exequias de Laurent tuvieron dos momentos significativos: ${ }^{42}$ la capilla ardiente en la sede del Comité Nacional con la presencia del propio Yrigoyen y su entierro en el cementerio de la Chacarita acompañado por una multitud de unas 
10.000 personas, con sendos discursos de homenaje. Andrés Ferreyra, presidente de la Cámara de Diputados, hizo referencia en su alusión a la inmolación del difunto, al señalar que "Los pueblos no encuentran la estabilidad de sus instituciones sino a través de cruentos y prolongados sacrificios", del que Laurent era claro ejemplo. El sacrificio del capitán por la causa radical no era más -a su entender- que otro jalón en de la marcha ascendente del país: "En la adversidad forjamos el carácter de nuestros hombres. Sea este muerto un símbolo y sea todo lo que hagamos en estos días por la grandeza, tranquilidad y gloria de la Nación Argentina. Soldado y correligionario: descansa en paz" ${ }^{43}$ Luego Bard habló en nombre del radicalismo santafesino, que se encontraba enfrascado en la elección provincial. En su discurso resaltó el lugar ocupado por los radicales de viejo cuño como Laurent en los combates del presente, ejemplo para los jóvenes sobre la entrega que implicaba la misión histórica exaltada por el radicalismo:

Aquella vieja guardia que ilustrara en jornadas memorables como la del Parque, la del 93, y la de 1905 (...) debió salir de su jubileo, abandona las satisfacciones de una breve paz civil, para reintegrarse al gran ejército republicano, en los puestos de vanguardia, desde donde se alecciona a las jóvenes generaciones con la brillante experiencia de los veteranos del sacrificio. De esta vieja guardia formaba parte el capitán Eduardo Laurent, ¿cómo extrañar, pues, que fuera uno de los primeros en acudir al llamado premioso de las circunstancias? (como se citó en Peretti, 2016, p. 111)

Atilio Larco, en representación del Centro de Ex Revolucionarios Civiles y Militares de la UCR, hizo referencia por su parte al pasado glorioso de Laurent como combatiente radical y a la entrega y el coraje que lo caracterizaban, al expresar que "no hay ninguna provincia argentina, donde su planta no se haya posado para arrancar un laurel por la causa de sus amores: la UCR” (como se citó en Peretti, 2016, p. 113).

\section{Imagen 5}

Funeral de Eduardo Laurent en el Cementerio de la Chacarita de Capital Federal

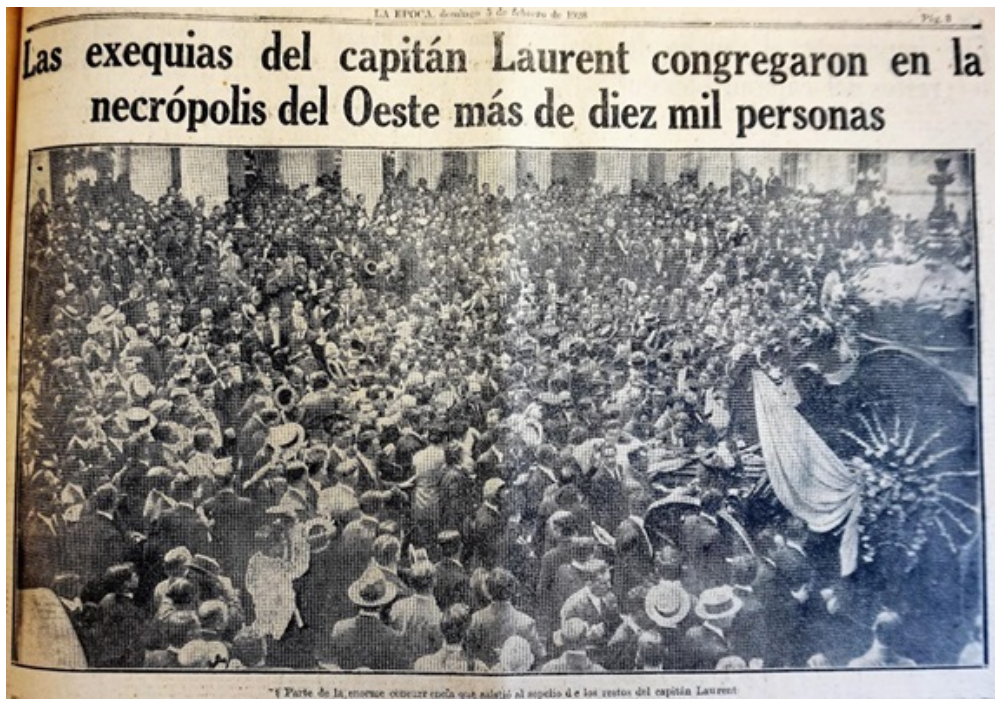

Fuente: (5 de febrero de 1928). La Época. BNRA. CABA.

De una u otra manera, los discursos en las exequias de Laurent abrevaron en los clásicos tópicos del martirologio radical: el pasado revolucionario, la concepción de los militantes como soldados de una causa nacional, el compromiso con 
una democracia popular que los radicales personalistas estaban convencidos de encarnar. Pero al mismo tiempo los sucesos de 1928 operaron una reformulación de la memoria partidaria, al asociar las luchas de los orígenes mitificados con las disputas de un presente democrático en donde el conflicto y la violencia política se habían instalado como un dato evidente para todos los contendientes.

Ciertamente, la inauguración del monumento a Alem insufó ánimos a los antipersonalistas al oponer un símbolo de conducción partidaria y de entrega sacrificial -un líder reconocido por viejos y nuevos radicales- al ascendiente de Yrigoyen en plena división de la UCR. Pero la polarización generada por la elección presidencial en la que este resultó reelecto, en lo que se consideró un verdadero "plebiscito" (Valdez, 2012), demuestra hasta qué punto los fenómenos de sacralización de la política nunca pueden considerarse una realidad sin fisuras ni el fundamento de identidades esenciales, pese a las declamaciones de sus voceros y pretendidos profetas.

\section{Conclusiones}

Al organizarse la conmemoración de la revolución del Parque para 1929, el club personalista "Hipólito Yrigoyen" de la $1^{\circ}$ sección anunció una gran velada nocturna y junto a los senadores Del Valle, Molinari y el presidente del Comité Nacional hablaría el general Juan Serrato. Este había sido uno de los oficiales de más alta graduación en el levantamiento de febrero de 1905 y, en el contexto de agitación de la breve segunda presidencia de Yrigoyen, su palabra llevaría tranquilidad a las filas partidarias. En efecto, venía de lanzar la segunda edición del folleto Ejército y militarismo en el que abordaba un tema candente de la de la primera posguerra mundial -por la militarización de la política en Europapero que resonaba en el clima local que desembocó en el golpe de Estado de 1930. Serrato abordaba los "problemas éticos del Ejército" y la necesidad de un "concepto civilista de la política" para evitar "toda acción antidemocrática" que desvirtuara "su verdadero carácter de mantenedor del orden y la integridad del país". ${ }^{4}$

En ese 1929 de movilizaciones opositoras y campañas de prensa que pedían la renuncia de Yrigoyen, el mensaje de los personalistas se focalizó en la defensa de la institucionalidad democrática. Tanto es así que Serrato se excusó de estar presente en el teatro por encontrarse de servicio y asegurar que sus funciones militares no debían mezclarse con sus adhesiones partisanas. No obstante, en su carta que se leyó en la velada felicitaba a sus "correligionarios" por "rememorar la fecha histórica del 26 de julio" que "regó con su sangre generosa la simiente de la idea en cuya persecución armó una vez más el brazo del pueblo". Al mismo tiempo denostaba a los "elementos esporádicos nacidos a la sombra de la generosidad de los que han mantenido enhiesta la bandera de aquella significación del civismo", ${ }^{2}$ en clara alusión a los radicales antipersonalistas.

El cariz que asumió esa conmemoración del hecho de armas, sobre el cual el radicalismo había erigido su mitología política, ilustra el sentido problemático de la idea de revolución en un contexto donde se había instalado la violencia política como ultima ratio para dirimir los conflictos. Como bien ha destacado la historiografía sobre el golpe de Estado de 1930, si los sectores nacionalistas que participaron en el mismo confiaban en una "revolución nacional" manu militari 
para transformar el régimen político del país en clave corporativa, existieron también otras motivaciones y lecturas entre los actores que confluyeron en el derrocamiento de Yrigoyen (Halperin Donghi, 2000).

Para la mayor parte de los políticos civiles implicados la revolución se interpretaba como una "reacción cívica" regeneradora frente a una situación de crisis de la que se responsabilizaba a un gobierno juzgado arbitrario y, según ha planteado González Alemán (2012), las referencias a la revolución del Parque como "acontecimiento-memoria" estuvieron a la orden del día en la coyuntura de 1929-1930 (en especial, pp. 53-54 y 64-66). Mientras que para figuras vinculadas al radicalismo en calidad de funcionarios de alto rango, como Matienzo citado arriba como publicista y ministro de Alvear-, la apelación a una instancia revolucionaria imponía otros dilemas y desafíos, para el intelectual liberal la cuestión tenía que ver con superar lo que calificaba de viejos males de la política argentina que 1890 no había logrado desterrar, sobre todo el personalismo. De forma que, antes que un régimen militar, la "obra revolucionaria” debía materializar el "cambio de opinión" mediante un perfeccionamiento del sistema representativo - no necesariamente centrado en la voluntad popular expresada en las urnas- que hiciera innecesarias futuras revoluciones. ${ }^{46}$

En este repaso por distintas posiciones sobre la revolución hacia 1930 se advierte bien -si se desbrozan los motivos sacralizados de las conmemoraciones de 1916-1930- que los radicales mantuvieron encendido, para propios y extraños, el recuerdo de una práctica política sobre la que se insistía como acción popular justificada contra un gobierno desquiciado. Pero como resultó patente pocos años después con la muerte y el masivo funeral de Yrigoyen en 1933, el radicalismo demostró la enorme capacidad de interpelación y movilización del culto a sus grandes líderes (Gayol, 2013). Algo que excedía con mucho los anteriores planteos de Oyhanarte y que no resulta extraño dada la cercanía temporal con la inauguración del monumento a Alem. La sedimentación de estos sentidos difícilmente podía ser controlada por sus promotores, en tanto la contingencia de los acontecimientos revitalizó pasiones y pertenencias que igualmente deben ser tenidas en cuenta para comprender la pervivencia de una identidad política como la radical. La vigilancia conmemorativa alrededor de las revoluciones, con su simbología, su sistematicidad y el compromiso sostenido por dirigentes y militantes, explica en gran medida por qué esta fuerza nacionalpopular logró afrontar sus divisiones en los años 1920 y encarar una nueva reorganización general en la década siguiente. Cómo todo ello logró influenciar a posteriores experiencias que dieron forma a sus rituales, celebraron sus gestas fundacionales y homenajearon a sus muertos en calidad mártires a lo largo del siglo $\mathrm{XX}$ argentino, es parte de otras historias.

\section{Referencias Bibliográficas}

Aboy Carlés, G. (2005). Populismo y democracia en la Argentina contemporánea. Entre el hegemonismo y la refundación. Estudios Sociales, 28(1), 125-149. https://doi. org/10.14409/es.v28i1.2553

Alem, L. (1928). Su vida, su obra, tragedia de su muerte, las doctrinas democráticas del fundador de la Unión Cívica Radical a través de documentos, discursos y escritos. Buenos Aires: Editorial Alem. 
Bianco, J. (1927). La doctrina radical. Buenos Aires: Rosso.

Camarero, H. (2007). A la conquista de la clase obrera. Los comunistas y el mundo del trabajo en la Argentina, 1920-1935. Buenos Aires: Siglo XXI.

Casquete, J. (2020). El culto a los mártires nazis. Alemania, 1920-1939. Madrid: Alianza.

Ferrari, M. (2008). Los políticos de la república radical. Prácticas políticas y construcción de poder. Buenos Aires: Siglo XXI.

Gayol, S. (2012). La celebración de los grandes hombres: funerales gloriosos y carreras post mortem en Argentina. Quinto Sol, 16(2), 1-29. https://doi.org/10.19137/q s.v16i2.525

Gayol, S. (2013). Ritual fúnebre y movilización política en la Argentina de los años treinta. PolHis, 12, 225-243. Recuperado de https://historiapolitica.com/datos/ biblioteca/muerte\%20y\%20politica_gayol.pdf

Gayol, S. y Palermo, S. (2018). Política de masas y cultura de masas: recorridos y convergencias. En S. Gayol y S. Palermo (Eds.), Política y cultura de masas en la Argentina de la primera mitad del siglo XX (pp. 13-27). Los Polvorines: Ediciones UNGS.

Gentile, E. (2007). El culto del littorio. La sacralización de la politica en la Italia fascista. Buenos Aires: Siglo XXI.

González Alemán, M. (2012). Alrededor de septiembre de 1930 en Argentina: ¿qué sentido para la "Revolución"? En M. González Alemán y E. Palieraki (Comps.), Revoluciones imaginadas. Itinerarios de la idea revolucionaria en América Latina contemporánea (pp. 51-72), Santiago, RIL.

González Alemán, M. (2014). Ciudadanos en la calle. Violencia, virilidad y civilidad política en la campaña presidencial porteña de 1928. The Hispanic American Historical Review, 94(3), 421-453. https://doi.org/10.1215/00182168-2694309

Gorelik, A. (2010). La grilla y el parque. Espaciopúblico y cultura urbana en Buenos Aires, 1887-1936. Bernal: Universidad Nacional de Quilmes.

Halperin Donghi, T. (2000). Vida y muerte de la República verdadera. Buenos Aires: Ariel.

Horowitz, J. (2015). El radicalismo y el movimiento popular (1916-1930). Buenos Aires: Edhasa.

Kertzer, D. (1988). Ritual, politics, and power. New Haven: Yale University Press.

Koselleck, R. (1998). Les monuments aux morts comme fondateurs de l'identité des survivants. Revue de Métaphysique et de Morale, 1, 33-61. Recuperado de https:/ /www.jstor.org/stable/40903577

Lvovich, D. (2006). El nacionalismo de derecha en Argentina. Desde sus orígenes hasta Tacuara. Buenos Aires: Capital Intelectual.

Martínez Mazzola, R. (2010). Socialismo y populismo, los comienzos de una relación conflictiva. La mirada del socialismo argentino sobre la Unión Cívica Radical (1890-1930). Anuario del Centro de Estudios Históricos "Prof. Carlos S. Segretti", (10), 210-230. https://doi.org/10.52885/2683-9164.v0.n10.23155

Matienzo, J. N. ([1910] 1917). El gobierno representativo federal en la República Argentina. Madrid: Editorial América.

Mc Gee Deutsch, S. (2003). Contrarrevolución en Argentina, 1900-1932. La Liga Patriótica Argentina. Bernal: Universidad Nacional de Quilmes.

Mosse, G. (1990). Fallen soldiers. Reshaping the memory of the World Wars. Oxford: Oxford University Press. 
Nora, P. (1997). Entre Mémoire et Histoire. La problématique des lieux. En P. Nora (Dir.), Les lieux de mémoire (pp. 23-43), t. I. París: Gallimard.

Oyhanarte, H. (1916). El Hombre. Buenos Aires: Mendersky.

Oyhanarte, H. (1999). De la oratoria a la acción. Buenos Aires: Círculo de Legisladores de la Nación Argentina.

Padoan, M. (2002). Jesús, el templo y los viles mercaderes. Un examen de la discursividad yrigoyenista. Bernal: Universidad Nacional de Quilmes.

Peretti. P. (2016). El asesinato del Capitán Laurent. Buenos Aires: CICCUS.

Persello, A. V. (2007). Historia del radicalismo. Buenos Aires: Edhasa.

Prost, A. (1997). Les monuments aux morts. Culte républicain? Culte civique? Culte patriotique? En P. Nora (Dir.), Les lieux de mémoire (pp. 199-223), t. I. París: Gallimard.

Reyes, F. (2016). “Conmemorar la revolución y sus mártires”. Sobre el lugar de un ritual político en los orígenes de la identidad del radicalismo. Estudios Sociales, 50(1), 41-76. https://doi.org/10.14409/es.v50i1.5947

Reyes, F. (2018), Las identidades políticas como creencias. Sobre la Unión Cívica Radical como "religión cívica". Pasado Abierto, 4(7), 252-264. Recuperado de htt ps://fh.mdp.edu.ar/revistas/index.php/pasadoabierto/article/view/2558

Reyes, F. (en prensa), El último refugio de la utopía. Horizontes del $1^{\circ}$ de Mayo en Argentina en tiempos de guerra y revolución. Historia, 54.

Tato, M. I. (2013). Una reflexión acerca de la cultura política de la derecha en la Argentina de entreguerras. Projeto Historia, 47, 125-152. Recuperado de https:// revistas.pucsp.br/index.php/revph/article/view/19005

Tato, M. I. (2007). Del crisol de razas a la Argentina desintegrada: un itinerario de la idea de nación, 1911-1932, Historia y Politica, (17), 153-173. Recuperado de htt ps://recyt.fecyt.es/index.php/Hyp/article/view/44567

Valdez, M.J. (2012). El "plebiscito" de Hipólito Yrigoyen: la campaña electoral de 1928 en la ciudad de Buenos Aires vista desde La Época”. Población \& Sociedad, 19(1), 75-103. Recuperado de https://cerac.unlpam.edu.ar/index.php/pys/article/view $/ 2844$

Zimmermann, E. (2008). “Los deberes de la revolución”. José Nicolás Matienzo y el golpe militar en la Argentina de 1930. Estudios Sociales, 34(1), 51-73. https://do i.org/10.14409/es.v34i1.2612

\section{Notas}

1 Una versión preliminar y parcial del presente artículo ha sido discutida en las XI Jornadas de Historia Moderna y Contemporánea, Universidad Nacional del Sur, Bahía Blanca (Argentina), 13-16 de abril de 2021. Los autores agradecen, además, los siempre pertinentes comentarios de Sandra Gayol y la atenta lectura y observaciones realizadas por Roy Hora, aunque las hipótesis sostenidas y posibles errores son exclusivamente propios.

2 Si bien se tiene en cuenta una amplia producción historiográfica sobre la política del cambio de siglo y el lugar que en ella ocupó el culto a los militantes y dirigentes muertos entendidos como "mártires" de una causa, se consideran particularmente aportes pioneros como los de G. Mosse (1990) y E. Gentile (2007), así como otros más recientes (Casquete, 2020).

3 Pese a que la efeméride de las revoluciones de 1893 estuvo relativamente presente en esos años, el trabajo hace hincapié en las de 1890 y 1905 en la medida en que los 
propios radicales les asignaron un sitial especial en la secuencia que interpretaban como preparación de su llegada al poder.

4 De acuerdo a la definición de Pierre Nora (1997), los lugares de la memoria no son producto de procesos espontáneos, sino de una sostenida organización y conmemoración de aniversarios, exaltación de personalidades y elogios fúnebres ( $\mathrm{p}$. 29).

5 1890-26 de Julio-1911 (29 de julio de 1911). Caras y Caretas, p. 78. Biblioteca Nacional de la República Argentina (BNRA), Ciudad Autónoma de Buenos Aires (CABA).

6 Para Gerardo Aboy Carlés la dimensión refundacional del mensaje del radicalismo formaba parte de una tensión pendular en la que se combinaba con su pretensión de representar al conjunto de la comunidad política nacional, un juego de ruptura y conciliación propio de los movimientos populistas (pp. 131-132). Aquí no se empleará esta conceptualización, al menos que se la pueda asociar al radicalismo como un movimiento nacional-popular que se presentaba como síntesis de los valores del nacionalismo y la democracia.

7 Como destaca Ricardo Martínez Mazzola (2010), en un partido como el PS que se pensaba parte de un movimiento internacional y que promovía la "aplicación de la ciencia a la política” incluso la caracterización de sus adversarios - sobre todo la UCRrequería ese esfuerzo de explicación teórica.

8 El principal diario partidario de la Capital Federal lo anunció en primera plana semanas antes de las elecciones presidenciales (10 de marzo de 1916). El Radical, p. 1. BNRA, CABA.

9 Para una problematización teórica e historiográfica de la identidad radical entendida por quienes se reconocían en ella como una religión cívica, cfr. Reyes (2018).

10 La fórmula presidencial (23 de marzo de 1916). El Radical, p. 1.

11 La cuña del mismo palo (7 de febrero de 1922). La Nación, p. 3 (destacado propio). BNRA, CABA.

12 Gayol y Palermo (2018) han explicado cómo los procesos de democratización política y de desarrollo de una cultura de masas se potenciaron mutuamente a inicios del siglo XX en Argentina (p. 15), lo que permite comprender la interacción entre "espectadores" y "actores" de las celebraciones radicales.

13 Aniversario del 4 de febrero (4 de febrero de 1916). El Radical, p. 2.

14 Las elecciones a gobernador provincial se habían realizado en noviembre del año anterior y habían culminado con triunfo radical. Aniversario del 4 de febrero de 1905 (5 de febrero de 1916). El Radical, p. 3.

15 Rememoración del 4 de febrero (4 de febrero de 1919). La Época, p. 1. BNRA, CABA

16 La revolución del 90 (25 de julio de 1919). La Época, p. 1.

17 Declaraciones de la Juventud Universitaria (16 de julio de 1923). La Época, p. 3.

18 Aniversario de la Revolución del 90 (23 de julio de 1923). La Época, p. 2.

19 El homenaje de ayer en la Recoleta a los caídos en la revolución del 4 de febrero de 1905 (4 de febrero de 1923). La Época, p. 2.

20 La revolución del 4 de febrero (3 de febrero de 1923). La Acción, p. 3. BNRA, CABA.

21 Mañana la UCR conmemorará el 39\% aniversario de la Revolución del 90 (25 de julio de 1929). La Época, p. 1.

22 Conmemoración del 4 de febrero (3 de febrero de 1916). El Radical, p. 3.

23 Conferencias de anoche (4 de febrero de 1916). El Radical, p. 2.

24 Partido Radical (12 de octubre de 1916). La Nación, p. 3.

2526 de Julio de 1890 (26 de julio de 1919). La Época, p. 2.

26 Los magníficos actos realizados ayer bajo los auspicios de la UCR (4 de febrero de 1926). La Época, p. 1.

27 Los actos conmemorativos de la Revolución del 4 de Febrero ( 5 de febrero de 1926). La Época, p. 2.

28 Aniversario de la Revolución del 90 (25 de julio de 1918). La Época, p. 2.

29 Conmemoración de la revolución del 90 (26 de julio de 1919). La Época, p. 2.

30 Los actos realizados en el 31 aniversario de la Revolución del año 1890 (27 de julio de 1921). La Época, p. 2. 
31 Sobre el ascenso de las derechas en la Argentina de la posguerra mundial, véase (entre otros) Lvovich (2006); Mc Gee Deutsch (2003) y Tato (2013; 2007).

32 Asamblea radical (20 de abril de 1897). El Tiempo, p. 1. BNRA, CABA; Monumento a Alem (4 de noviembre de 1902). El Municipio, p. 1. Centro de Estudios Históricos e Información Parque de España (CEHIPE), Rosario.

33 Monumento al Dr. Alem (7 de julio de 1918). La Época, p. 2.

34 Monumento al Dr. Alem (27 de julio de 1919). La Época, p. 2; Comisión Nacional pro monumento al Dr. Alem (20 de julio de 1920). La Época, p. 2.

35 El Monumento a Alem (14 de octubre de 1925). La Acción, p. 5.

36 Revistió lúcidos contornos la inauguración del monumento al Dr. Alem (11 de octubre de 1925). La Acción, p. 5.

37 Alrededor del monumento (10 de octubre de 1925). La Fronda, p. 3. BNRA, CABA.

38 Decididamente, la fusión radical es un hecho (11 de octubre de 1925). La Acción, p. 1.

39 La integración de oficiales del Ejército, y en general de militares, en los elencos políticos de las décadas de 1910 y 1920 ha sido analizada por Marcela Ferrari, con especial énfasis en el prestigio que acarreaba dentro de las filas del radicalismo la participación en los alzamientos armados del cambio de siglo (Ferrari, 2008, pp. 211-238).

40 Para la reconstrucción de los acontecimientos y las implicancias del antipersonalismo en el asesinato, véase Peretti (2016, pp. 74-93), aunque esto no implica suscribir a su interpretación del hecho como prolegómeno del "Estado terrorista” en Argentina.

41 La conmemoración del 4 de febrero (3 de febrero de 1928). La Época, p. 3.

42 Cabe mencionar que en esos años se sucedieron distintos funerales de militantes e importantes dirigentes radicales - uno de los más significativos fue el del vice-presidente electo en 1928, Francisco Beiró, que no llegó a asumir el cargo- que constituyen un corpus significativo a ser estudiado desde la perspectiva de la ritualización del culto a los muertos, pero que por una cuestión de espacio han quedado fuera de este análisis.

43 Oración fúnebre del diputado nacional Andrés Ferreyra en el funeral del Capitán Laurent en el Comité Nacional de la UCR (5 de febrero de 1928). La Época, p. 3.

44 Ejército y militarismo (febrero de 1929). La Literatura Argentina. Revista Bibliográfica (año I, No 6), p. 28. Recuperado de: https://ahira.com.ar/ejemplares/la-literatura-arg entina-no-6/.

45 La gran velada cívica en el gran cine-teatro Fénix (27 de julio de 1929). La Época, p. 2.

46 El análisis de las reflexiones de Matienzo pertenece a Zimmermann (2008, en especial pp. 63-65). 